\title{
Prevalence of dysfunctional but viable myocardium in patients with ischemic cardiomyopathy - results from clinical scans performed in 2010-2014 at four U.S. hospitals
}

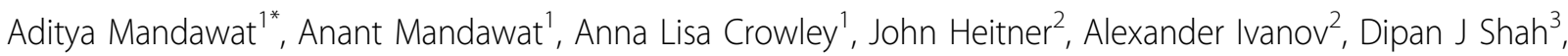 \\ Faisal Nabi ${ }^{3}$, Afshin Farzaneh-Far ${ }^{4}$, Han W Kim', Wolfgang G Rehwald ${ }^{5}$, Raymond Kim', Robert Judd', Igor Klem
}

From 19th Annual SCMR Scientific Sessions

Los Angeles, CA, USA. 27-30 January 2016

\section{Background}

Assessment of viability in patients with ischemic cardiomyopathy (ICM) prior to possible revascularization has fallen out of favor after the STITCH trial, which failed to demonstrate a benefit of echocardiography or nuclear viability testing. CMR assessment of viability by directly visualizing the transmural extent of both viable and nonviable myocardium offers unique advantages which have not been explored in large trials. Several small studies have shown significant contractile improvement after revascularization of dysfunctional segments with residual viability by CMR. The objective of this study was to determine the prevalence of residual viability over the entire range of severity of dysfunction in patients with ICM.

\section{Methods}

Data analysis was performed on a cloud-based system that is currently receiving de-identified searchable data from electronically-signed clinical reports with full DICOM datasets for 23,275 consecutive CMR exams performed at four U.S. hospitals from Jan 1, 2010 through Dec 31, 2014. At the time of analysis 8,242 datasets were available, and analysis of all 23,275 is expected by the end of 2015. All data were derived from CMR reports that had been electronically signed by board-certified physicians with Level 3 CMR training. ICD-9 codes $(410,411,412,413,414)$ were used to identify patients with a history of coronary artery disease. Regional contractility (normal, mild/moderate hypokinesia, severe hypokinesia, akinesia, dyskinesia) and transmural extent of hyperenhancement (0\%, 1-25\%, 26$50 \%, 51-75 \%, 76-100 \%$ ) were quantified using a standard seventeen-segment model. Significant viability was defined as $\leq 50 \%$ transmural extent of hyperenhancement.

\section{Results}

Of the 1,763 patients with coronary artery disease undergoing CMR, 1,195 patients had chronic ischemic heart disease. Among these, 218 (18\%) patients had a left ventricular ejection fraction $\leq 40 \%$ (median 30 ) and were included in the subsequent analyses. The median age of these patients was 66 years (IQR 16 years), 57\% were male, $28 \%$ had a history of diabetes mellitus, $56 \%$ had a history of hypertension, and $49 \%$ had a history of hyperlipidemia, $15 \%$ were active smokers. In total 3,706 segments were analyzed, of which 2,898 (78\%) had abnormal contractility. Among all dysfunctional segments, 2,516 segments (87\%) showed significant viability (Table 1 ). Even among the 1,709 segments with severe dysfunction (severe hypokinesia, akinesia, dyskinesia) 1,338 segments (78\%) showed significant viability.

\section{Conclusions}

A significant proportion of severely dysfunctional segments in patients with ICM demonstrated residual viability as assessed by CMR, which was shown previously to correlate with a high degree of functional improvement after revascularization. The utility of viability assessment by CMR in guiding revascularization in patients with ICM should be revisited.

'Cardiology, Duke University Hospital, Durham, NC, USA

Full list of author information is available at the end of the article 
Table 1 Severity of segmental dysfunction according to presence or absence of viable myocardium

\begin{tabular}{ccccc}
\hline \multicolumn{5}{c}{ Severity of Segmental Dysfunction } \\
\hline Hyperenhancement & Mild/Moderate Hypokinesia (N = 1189) & Severe Hypokinesia (N = 1058) & Akinesia (N = 535) & Dyskinesia (N = 116) \\
\hline $0-50 \%$ & $1178(99 \%)$ & $1000(95 \%)$ & $302(56 \%)$ & $36(31 \%)$ \\
$51-100 \%$ & $11(1 \%)$ & $58(5 \%)$ & $233(44 \%)$ & $80(69 \%)$ \\
\hline
\end{tabular}

\section{Authors' details}

${ }^{1}$ Cardiology, Duke University Hospital, Durham, NC, USA. ${ }^{2}$ New York

Methodist Hospital, Brooklyn, NY, USA. ${ }^{3}$ Houston Methodist DeBakey Heart \&

Vascular Center, Houston, TX, USA. ${ }^{4}$ University of Illinois at Chicago, Chicago,

IL, USA. ${ }^{5}$ Siemens Healthcare, Chapel Hill, NC, USA.

Published: 27 January 2016

doi:10.1186/1532-429X-18-S1-01

Cite this article as: Mandawat et al:: Prevalence of dysfunctional but

viable myocardium in patients with ischemic cardiomyopathy - results

from clinical scans performed in 2010-2014 at four U.S. hospitals.

Journal of Cardiovascular Magnetic Resonance 2016 18(Suppl 1):O1.
Submit your next manuscript to BioMed Central and take full advantage of:

- Convenient online submission

- Thorough peer review

- No space constraints or color figure charges

- Immediate publication on acceptance

- Inclusion in PubMed, CAS, Scopus and Google Scholar

- Research which is freely available for redistribution

Submit your manuscript at www.biomedcentral.com/submit
C Biomed Central 